\title{
Promoting Health Behavior Change in Canada: A Quality Improvement Project Integrating Prevention and Wellness in Frontline Care
}

\author{
Kiran Rabheru',2, David Conn²,3, Daria Parsons², Ariane S. Massie², Julie Mitchell2, \\ Michael Vallis ${ }^{4}$, Claire Checkland ${ }^{2}$, Keri-Leigh Cassidy ${ }^{5}$ \\ ${ }^{1}$ Department of Psychiatry, University of Ottawa, Ottawa, Canada \\ ${ }^{2}$ Canadian Coalition for Seniors' Mental Health, Toronto, Canada \\ ${ }^{3}$ Department of Psychiatry, University of Toronto, Toronto, Canada \\ ${ }^{4}$ Department of Psychology, Dalhousie University, Halifax, Canada \\ ${ }^{5}$ Department of Psychiatry, Dalhousie University, Halifax, Canada \\ Email: kiranrabheru@hotmail.com, dariaparsons@rogers.com, arianes@yorku.ca, juliespencemitchell@gmail.com, \\ Claire.checkland@gmail.com,dconn@baycrest.org, tvallis@dal.ca, keri-leigh.cassidy@nshealth.ca
}

How to cite this paper: Rabheru, K., Conn, D., Parsons, D., Massie, A.S., Mitchell, J., Vallis, M., Checkland, C. and Cassidy, K.-L. (2021) Promoting Health Behavior Change in Canada: A Quality Improvement Project Integrating Prevention and Wellness in Frontline Care. Open Journal of Psychiatry, 11, 125-137. https://doi.org/10.4236/ojpsych.2021.113011

Received: March 25, 2021

Accepted: May 9, 2021

Published: May 12, 2021

Copyright $\odot 2021$ by author(s) and Scientific Research Publishing Inc. This work is licensed under the Creative Commons Attribution International License (CC BY 4.0).

http://creativecommons.org/licenses/by/4.0/

\begin{abstract}
Background: The critical need for Health Behaviour Change (HBC) for preventative care has been highlighted by the COVID-19 pandemic. This quality improvement project assessed the effectiveness and acceptability of Fountain of Health $\mathrm{HBC}$ tools as a minimal intervention for primary and secondary prevention among Canadian clinicians and their patients. Methods: Clinicians received $\mathrm{HBC}$ education and tools (paper tools and app-based) to assist their patients in setting a S.M.A.R.T (Specific, Measurable, Action-oriented, Realistic, Time-limited) goal at baseline and assessed four weeks later. Primary outcome measures were: 1) patient self-report of success at goal attainment; 2) patient self-reported evaluation of change in well-being and health attitudes; and 3) clinician experience and engagement. Results: A total of 2184 clinicians received HBC education. Of these, 759 clinicians registered to participate in the project. 961 patients set S.M.A.R.T. HBC goals using either the paper tools (PT) or the app format. Patient data revealed nearly all patients ( $89 \%$ of PT users and $90 \%$ of app users) at least partially succeeded in attaining their goal at a four-week follow-up. Most patients (85\% of PT and $80 \%$ of app users) also reported improvement in their well-being. A significant difference in health beliefs and attitudes was found in both PT ( $\mathrm{p}<$ $0.001)$ and app users $(p=0.003)$. Conclusions: HBC is challenging. Educating and providing clinicians with $\mathrm{HBC}$ tools as a minimal intervention was found to be a successful health prevention strategy to improve patient
\end{abstract}


well-being and health attitudes, and achieve S.M.A.R.T. goals. Results show $\mathrm{HBC}$ tools, education, and support for clinicians are both acceptable and effective for $\mathrm{HBC}$ in frontline care. These findings are relevant and timely given greater reliance on virtual care in the wake of the COVID-19 pandemic. Further research with rigorous methodology is needed to implement programs to achieve sustainable HBC to promote health on a large scale.

\section{Keywords}

Behaviour Sciences, Mental Health, Medical Education, Primary and Secondary Prevention, Health Behavior Change, Risk Reduction, Tools for Health and Wellness, Positive Psychiatry

\section{Introduction}

The critical role of Health Behaviour Change (HBC) to optimize patients' social connections, cognitive, physical, and mental health has been highlighted by the COVID-19 pandemic [1]. Its impact has been disproportionately felt by older persons who have suffered substantial mortality, morbidity, and a sense of severe social isolation and loneliness [2]. There has never been a more compelling need to promote virtual care [3], e-health [4] and $\mathrm{HBC}$ as part of primary or secondary prevention strategies to reduce the risk of chronic medical conditions, including depression [5] [6] [7], dementia [8] [9] [10], and possibly suicide [11]. Yet, clinicians cite lack of tools and training for implementing $\mathrm{HBC}$ in practice [12] [13] [14]. Closing this gap would simplify HBC conversations by providing useful resources, with direct benefits to patients and clinicians [15], and improve quality of care [16]. Positive psychiatry, a new branch of healthcare, invites a focus on wellness promotion in research and practice, in addition to illness prevention [17].

The Fountain of Health $(\mathrm{FoH})$ is a Canadian positive psychiatry initiative that incorporates evidence-based tools to influence $\mathrm{HBC}$, well-being, and health attitudes [18] [19] by incorporating S.M.A.R.T. goal setting [20] [21]. Effective health behavior goals and interventions are minimal ones, small and doable enough so clinicians and patients alike are able to achieve them. The acronym "S.M.A.R.T." stands for the following health goal qualities:

Specific: How specifically will you achieve this goal? What concrete steps will you need to take?

Measurable: How will you measure progress? How often will you do this activity? For how long?

Action-Oriented: Is the health goal dependent on actions? What will those actions be?

Realistic: Is this goal realistic? Can this be achieved in the next few weeks? Are there obstacles to overcome, or supports that could help?

Time-Limited: What times of day or days of the week are best to work on this 
goal?

The FoH's HBC minimal intervention tools consist of a paper-based Toolkit [22] (PT) and a Wellness App (app) [23] focused on known promotors of health from five lifestyle domains: physical activity [24], social activity [25], cognitive activity [26], seeking mental healthcare when needed [27], and positive thinking [28]. This project assessed the acceptability and effectiveness of the FoH HBC tools among clinicians and patients.

This project offers several novel contributions to the field of psychiatry. This is the first initiative of which we are aware to nationally scale effective HBC methods in frontline care to promote patients' health and well-being. The methods used captured not only the impact of HBC education on clinicians' practice [18], but also on patients' health behaviors and attitudes, representing a novel contribution to knowledge translation literature in psychiatry. This project also offers an innovative, positive psychiatry, public health approach to promote successful aging and well-being [29]. The availability of effective, scalable virtual HBC e-tools and the Wellness App to promote health and well-being is particularly relevant today in the context of COVID-19.

\section{Methods}

The Brain Health and Wellness (BHW) project was a Canadian positive psychiatry quality improvement (QI) project based on a pilot study conducted in the province of Nova Scotia in Canada that demonstrated the effectiveness of the FoH HBC tools [18] [19]. The BHW project was co-led by the Canadian Coalition for Seniors' Mental Health (CCSMH) [30] and the Fountain of Health [31].

\subsection{Clinician Recruitment}

Clinicians from various disciplines and practice-settings were contacted via the CCSMH's network, through healthcare organizations, and individual professional contacts. Clinicians received HBC education in English or French, through in-person, live webinars, or pre-recorded web-based sessions. Clinicians received a paper-based and an electronic version of the FoH Toolkit, including a Goal Documentation Sheet, Patient Take Home Goal Sheet, and the Health and Resilience Questionnaire (HRQ-Pre- and Post).

\subsection{Patient Recruitment}

No stringent patient inclusion criteria were applied. Clinicians were encouraged to invite willing and able patients aged 40 years and over without a diagnosis of dementia to participate. Clinicians gathered patient data over the course of two patient visits between March and September 2019.

Visit 1: Clinicians worked collaboratively with patients to establish a baseline of each of the five health domains on the HRQ-Pre and encouraged patients to set a S.M.A.R.T. goal in one domain.

Visit 2: Approximately four weeks later, clinicians followed up to assess the 
patient's success at goal attainment, well-being and health attitudes. Clinicians could conduct the follow-up in-person, by telephone, or delegate it to another clinician. Patient forms were returned by fax, email or using a postage-paid envelope. Support was provided to clinicians by coaches either in-person, via email or telephone.

\subsection{Outcome Measures}

The primary outcome measures were: 1) patient self-report of success at goal attainment; 2) subjective evaluation of change in well-being and health attitudes; and 3) clinician experience and engagement.

\subsection{Data Analysis}

Goal attainment at the four-week follow-up was measured using a validated Goal Attainment Scaling [32] [33] [34] (GAS) instrument in which participants chose among the following: no change, partially achieved, fully achieved, exceeded. Subjective change in well-being related to working toward the goal was measured using a similar scale in which participants chose among the following: no change, slightly improved, moderately improved, greatly improved. Subjective change in health attitude was assessed with a pre/post HRQ composed of five ten-point visual analogue scales assessing health beliefs and attitudes on key health domains [35] [36] [37].

\subsection{Ethics Approval}

The project was deemed to be REB exempt by the Ottawa Health Sciences Network, Baycrest Health Sciences, Nova Scotia Health Authority, and University of British Columbia, as a QI project. No personal identifying patient or clinician data were collected.

\section{Results}

\subsection{Clinician Acceptability}

Figure 1 outlines the number of clinicians who participated in in-person versus webinar education. Of the 2184 clinicians who participated in education, 759 registered to participate in the BHW Project.

Table 1 and Table 2 outline the province of practice and professional role of registered clinicians. Clinicians from across Canada participated. The largest percentage of registered clinicians was found in the following professional roles: $25 \%$ were nurses/nurse practitioners; $19 \%$ were physicians and $19 \%$ were social workers.

Figure 2 highlights feedback received from a follow-up survey that was sent to registered clinicians with a response rate of $20 \%(n=155)$. Eighty-five percent of clinicians who responded to the survey reported that the PTs were easy to use; 75\% reported that the Wellness App was easy to use. Eighty-two percent of respondents indicated that the BHW Project was a positive experience. 


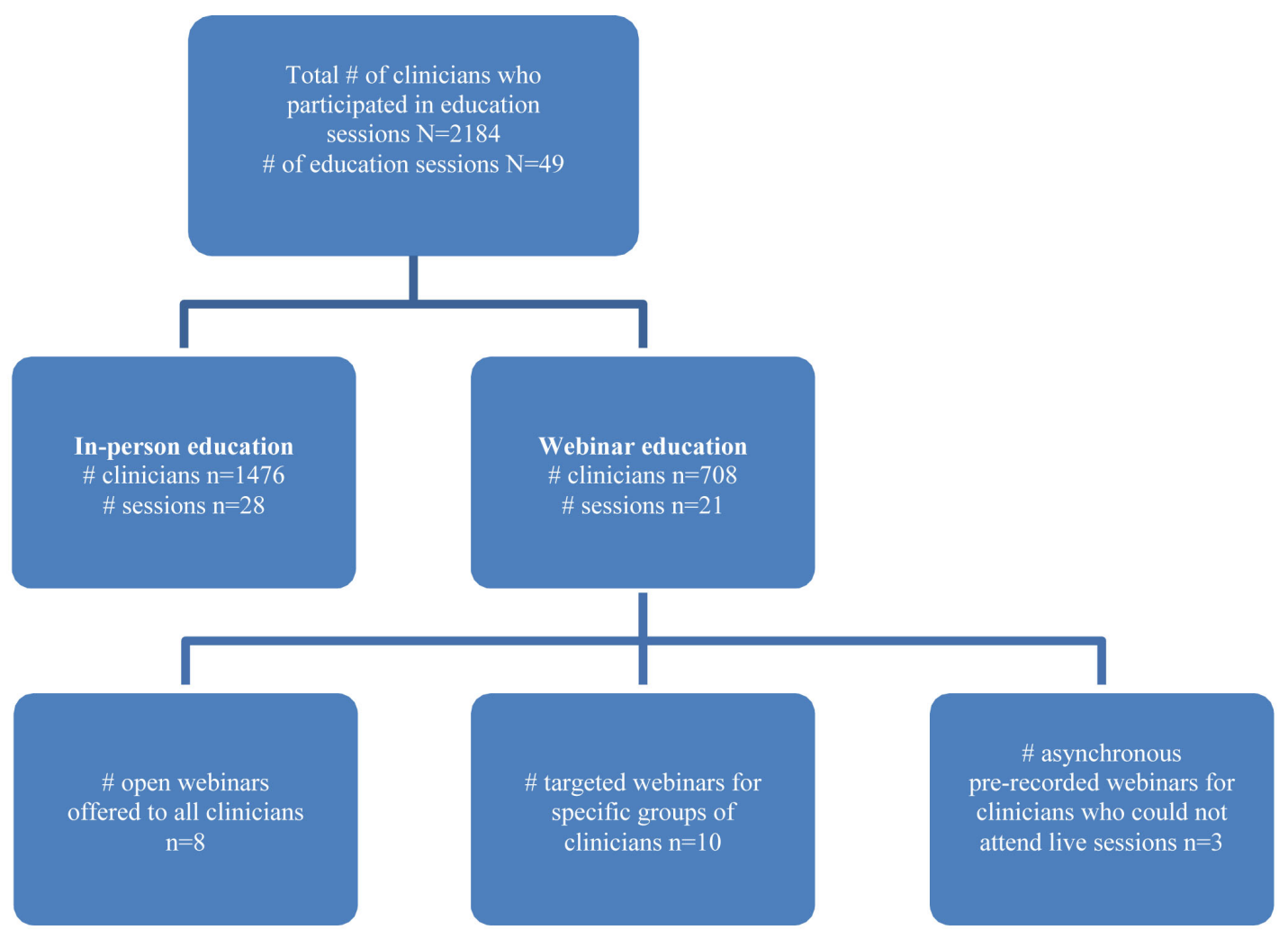

Figure 1. Clinician education summary.

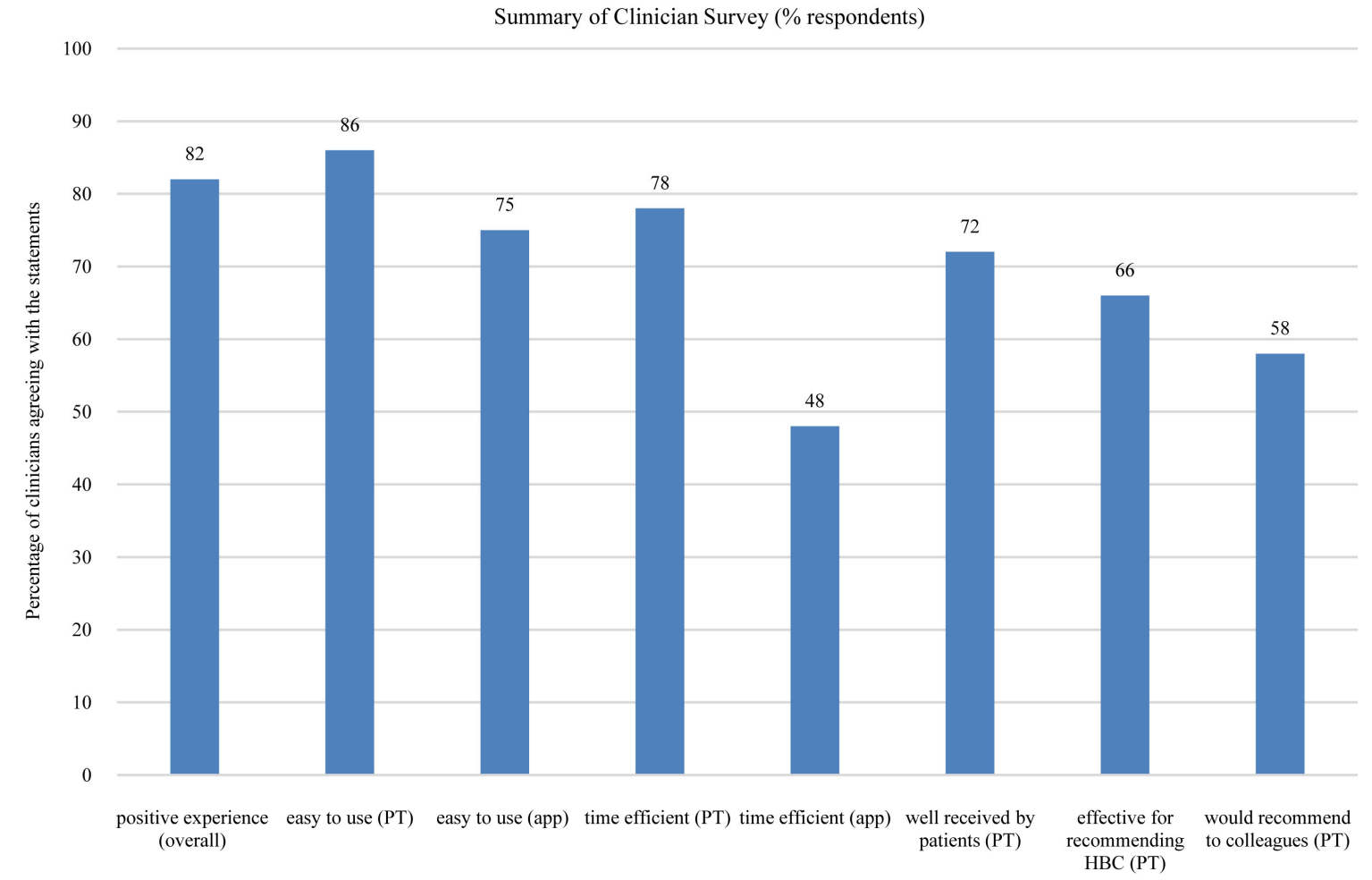

— Survey Questions

Figure 2. Clinician follow-up survey results. 
Table 1. Characteristics of registered clinicians by geographical location.

\begin{tabular}{ccc}
\hline Geographical & \multicolumn{2}{c}{ Number of registered clinicians } \\
\cline { 2 - 3 } location & Number of Clinicians & Percent \\
\hline Newfoundland & 3 & $0.4 \%$ \\
Nova Scotia & 137 & $18.1 \%$ \\
Prince Edward Island & 8 & $1.1 \%$ \\
New Brunswick & 87 & $11.5 \%$ \\
Quebec & 13 & $1.7 \%$ \\
Ontario & 355 & $46.8 \%$ \\
Manitoba & 18 & $2.4 \%$ \\
Saskatchewan & 10 & $1.3 \%$ \\
Alberta & 42 & $5.5 \%$ \\
British Colombia & 65 & $8.6 \%$ \\
Yukon & 5 & $0.7 \%$ \\
International & 16 & $2.1 \%$ \\
Total & 759 & $100 \%$ \\
\hline
\end{tabular}

Table 2. Characteristics of registered clinicians by professional role.

\begin{tabular}{ccc}
\hline \multirow{2}{*}{ Clinician } & \multicolumn{2}{c}{ Number of registered clinicians } \\
\cline { 2 - 3 } Discipline & Number of Clinicians & Percent \\
\hline Nurse/NP & 192 & $25.4 \%$ \\
Social Worker & 146 & $19.2 \%$ \\
Physician & 140 & $18.5 \%$ \\
Occupational Therapist & 52 & $6.9 \%$ \\
Mental Health and Addictions & 40 & $5.3 \%$ \\
Educator & 30 & $4.0 \%$ \\
Recreational Therapist & 24 & $3.2 \%$ \\
Dietician & 23 & $3.0 \%$ \\
Physical Therapist & 21 & $2.8 \%$ \\
Pharmacist & 10 & $1.3 \%$ \\
Psychologist & 9 & $1.6 \%$ \\
Psychotherapist & 4 & $0.5 \%$ \\
Other & 68 & $9.0 \%$ \\
Total & 759 & $100 \%$ \\
\hline
\end{tabular}

\subsection{Patient Acceptability}

A total of 961 patients used PTs and/or app; of these, 380 patients used PTs and 581 used the app, with clinician support. Only 18\% [106/581] of app users completed Visit 2 versus 92\% [349/380] who used PTs. The average age of app users was 16 years younger than PT users (Table 3 ) and $68 \%$ of PT users versus $81 \%$ of app users were female (Table 4). Fifty-seven percent of patients selected their goal in the physical activity domain. The goal domains that patients selected are outlined in Table 5. 
Table 3. Age of patients by intervention format (paper tools and app users).

\begin{tabular}{cccc}
\hline \multirow{2}{*}{ Intervention format } & \multicolumn{3}{c}{ Age of patients } \\
\cline { 2 - 4 } & $\boldsymbol{N}$ & Mean Age (years) & Age Range (years) \\
\hline Paper Tool (PT) Users & 362 & 67.8 years & $38-59$ \\
Wellness App Users & 550 & 52.4 years & $18-95$ \\
\hline
\end{tabular}

Table 4. Sex of patients by intervention format (paper tools and app users).

\begin{tabular}{ccccc}
\hline & \multicolumn{4}{c}{ Intervention format } \\
\cline { 2 - 5 } Patient Sex & \multicolumn{2}{c}{ Paper Tool Users } & \multicolumn{2}{c}{ App Users } \\
\cline { 2 - 5 } & $\mathbf{n}$ & Valid Percent & $\mathbf{n}$ & Valid Percent \\
\cline { 2 - 5 } Male & 118 & $32.1 \%$ & 103 & $18.8 \%$ \\
Female & 250 & $67.9 \%$ & 443 & $80.7 \%$ \\
Other & 0 & - & 3 & $0.5 \%$ \\
Total & 368 & & 549 & \\
\hline
\end{tabular}

Table 5. Patient goal domains by intervention format (paper tools and app users).

\begin{tabular}{ccccc}
\hline & \multicolumn{3}{c}{ Intervention format } \\
\cline { 2 - 5 } $\begin{array}{c}\text { Health Domains Category of } \\
\text { S.M.A.R.T. Goal Setting }\end{array}$ & \multicolumn{2}{c}{ Paper Tool Users } & \multicolumn{2}{c}{ App Users } \\
\cline { 2 - 5 } & $\mathrm{n}$ & Valid Percent & $\mathrm{n}$ & Valid percent \\
\hline Physical activity & 212 & $56.4 \%$ & 258 & $62.1 \%$ \\
Social activity & 68 & $18.1 \%$ & 52 & $12 . .5 \%$ \\
Mental health & 42 & $11.1 \%$ & 36 & $8.7 \%$ \\
Brain challenge & 38 & $10.1 \%$ & 34 & $8.2 \%$ \\
Positive thinking & 16 & $4.3 \%$ & 36 & $8.7 \%$ \\
Total & 376 & & 415 & \\
\hline
\end{tabular}

\subsection{Effectiveness for Patient Goal Attainment, Well-being, and Health Attitudes}

Patient Goal Attainment and Well-Being Scores indicated that 89\% (309/349) of PT users and 90\% (95/106) of app users at least partially attained their goal (Table 6). At least a slight improvement in well-being was reported by $85 \%$ (286/338) of PT users and 80\% (74/92) of app users. Statistically significant differences in health attitudes were observed in Pre-/Post-HRQs (PT users $\mathrm{p}<$ 0.001 and app users $p=0.003$ ) using t-tests.

\section{Discussion}

This project demonstrated both the acceptability and effectiveness of a minimal intervention-clinicians using $\mathrm{HBC}$ tools with patients. Acceptability among clinicians was demonstrated by voluntary attendance at $\mathrm{HBC}$ education and use of the tools by a large, diverse group of clinicians from a variety of busy, frontline clinical settings. The effectiveness of the HBC tools was demonstrated 
Table 6. Patient goal attainment and well-being scores.

\begin{tabular}{cccccc}
\hline \multirow{2}{*}{$\begin{array}{c}\text { Health Domains Category of } \\
\text { S.M.A.R.T. Goal Setting }\end{array}$} & \multicolumn{4}{c}{ Paper Tool Users } & \multicolumn{2}{c}{ App Users } \\
\cline { 2 - 6 } Measure & Response Category & $n$ & Valid Percent & $n$ & Valid percent \\
\hline \multirow{2}{*}{ Goal } & Exceeded & 56 & $16.0 \%$ & 8 & $7.5 \%$ \\
Attainment & Fully & 111 & $31.8 \%$ & 28 & $26.4 \%$ \\
& Partially & 142 & $40.7 \%$ & 59 & $55.7 \%$ \\
& No Change & 40 & $11.5 \%$ & 11 & $10.4 \%$ \\
& Total & 349 & & 106 & \\
Gell-being & Greatly & 46 & $13.6 \%$ & 5 & $5.4 \%$ \\
& Moderately & 121 & $35.8 \%$ & 30 & $32.6 \%$ \\
& Slightly & 119 & $35.2 \%$ & 39 & $42.4 \%$ \\
& No Change & 52 & $15.4 \%$ & 18 & $19.6 \%$ \\
& Total & 338 & & 92 & \\
\hline
\end{tabular}

by the high rate of patients' success at S.M.A.R.T. goal attainment and enhanced self-reported well-being and health attitudes by working collaboratively with their clinicians. The vast majority of patients at least partially attained their HBC goal (89\% PT users; 90\% app users) and reported improved well-being. Improvement in well-being was reported by a majority of PT users (85\%) and app users $(80 \%)$. Note that additional data analysis to compare results of PT versus app users in this project are published elsewhere and highlight the importance of the role of clinician-patient relationship for outcome measures as well as the importance of S.M.A.R.T. goal setting methodology [38].

The results of the present study are important, suggesting FoH HBC tools facilitated effective, shared decision-making between clinicians and patients, making HBC advice personally relevant, more motivating, and bridging the intention-behaviour gap for patients [15] [38]. Clinicians in this project were successful in incorporating $\mathrm{FoH} \mathrm{HBC}$ tools into their practice, and in promoting primary and secondary prevention during routine care to enhance patients' physical, mental and social well-being.

The BWH project and its results offer several significant contributions to the field of psychiatry. This is the first psychiatric initiative of which we are aware to nationally scale effective minimal intervention $\mathrm{HBC}$ methods in frontline care. The scope and nature of the project also responds to a recent call to action to take a positive psychiatry approach to go beyond illness prevention to promote successful aging and well-being on a public health scale [28]. Methods used captured positive changes not only in clinicians' practice, but also in patients' health behaviours and attitudes; the inclusion of both clinician and patient behaviour measures is a significant contribution to health knowledge translation literature. The accessible, online resources including The Wellness App to support clinicians to promote $\mathrm{HBC}$ and well-being in patients are relevant innovations in the 
context of COVID-19 and need for effective population health promotion tools.

Future research should compare the outcomes of HBC interventions with the use of technology-augmented clinician support to those using technology independently, without clinician support. Further longer-term research with rigorous methodology is needed to not only implement $\mathrm{HBC}$ programs, but also to sustain HBC on a large scale [39].

\section{Limitations}

Despite substantial investment of resources and effort, there was significant attrition in the final uptake of the HBC tools in practice as measured by PT forms returned, reinforcing that behavior change is inherently challenging for patients and clinicians [40]. This is consistent with HBC literature where application of knowledge-into-practice lags significantly behind rapidly evolving science [41].

Berkman outlines the neuroscience of goals and behavior change, the way people set, pursue and eventually succeed or fail in accomplishing their goals [42]. Extrapolating and generalizing from these results must be done with some prudence as it was a QI project, where clinicians and patients volunteered to participate in a non-randomized, non-blinded fashion with no control group. Most patients were aged 40 years and over, given the focus was on $\mathrm{HBC}$ targeted at reducing the risk of age-related ailments. A self-selection bias for clinicians and patients is inherent in terms of being attracted to a project on HBC. The high levels of reported success in goal attainment may have been influenced by the desire of both patients and clinicians to report positive results and possibly greater likelihood of follow-up by patients who were successful at attaining their goal. Completion rates of Visit 2 by app users were five times lower than PT users suggesting that reliance on technology alone may have its limitations especially for older populations. The quality and degree of clinician-patient interaction was likely a key factor influencing the outcome [38] [41].

\section{Conclusions}

This novel Canadian QI project demonstrated that, with education and support, evidence-based HBC tools (PT and a web-based app) are acceptable to and can be implemented successfully by a variety of clinicians across many practice settings. When FoH HBC tools were utilized by clinicians in frontline care, patients reported benefits in health outcomes as measured by successful S.M.A.R.T. goal setting and improved well-being and health attitudes.

The positive impact of a minimal, scalable HBC intervention on clinicians' practice and a majority of their patients' health behaviors and attitudes is a noteworthy finding. This is the first positive psychiatry initiative of which we are aware to nationally scale an effective HBC method in frontline care to promote patient well-being on a public health scale [28]. The acceptability, effectivenesss, and accessibility of these virtual resources to clinicians and the public to promote well-being is relevant today in the context of COVID-19. These HBC tools 
may have utility for primary and secondary prevention, employing in-person or virtual clinical encounters, offering an important and timely intervention for many patients to better manage stress and promote well-being.

\section{Acknowledgements}

Dr. Chandi Chandrasena, Site Lead, Ottawa, Ontario;

Dr. Linda Gobessi, Site Lead, Ottawa, Ontario;

Dr. Paul Blackburn, Site Lead, Vancouver, British Columbia;

Dr. Cindy Grief, Site Lead, Toronto, Ontario;

Dr. Beverley Cassidy, Lead, the Wellness App Development Team;

Ms. Laurie Low, Project Coordinator, Vancouver, British Columbia;

Ms. Jean Dexter Robinson, Project Coordinator, Halifax, Nova Scotia.

\section{Funded}

The BHW Project was funded by the Centre for Aging and Brain Health Innovation.

\section{Conflicts of Interest}

The authors declare no conflicts of interest regarding the publication of this paper.

\section{References}

[1] Dixon-Fyle, S., Gandhi, S., Pellathy, T. and Spathanou, A. (2012) Changing Patient Behaviour: The Next Frontier in Healthcare Value. Health International, No. 12, 65-73.

https://healthcare.mckinsey.com/sites/default/files/791750_Changing_Patient_Beha vior_the_Next_Frontier_in_Healthcare_Value.pdf

[2] Hwang, T.J., Rabheru, K., Peisah, C., Reichman, W. and Ikeda, M. (2020) Loneliness and Social Isolation during the COVID-19 Pandemic. International Psychogeriatrics, 26, 1-4. https://doi.org/10.1017/S1041610220000988

[3] Bhyat, R. (2020) Canada's “New Normal” Must Include Virtual Care. https://healthydebate.ca/opinions/new-normal-include-virtual-care

[4] Leite, H., Hodgkinson, I.R. and Gruber, T. (2020) New Development: "Healing at a Distance"-Telemedicine and COVID-19. Public Money \& Management, 40, 483-485. https://doi.org/10.1080/09540962.2020.1748855

[5] Sarris, J., O’Neil, A., Coulson, C.E., Schweitzer, I. and Berk, M. (2014) Lifestyle Medicine for Depression. BMC Psychiatry, 14, 107.

https://doi.org/10.1186/1471-244X-14-107

[6] Norton, M.C., Fauth, E.B. and Weyerman, J. (2017) Making Lifestyle Choices to Reduce Late-Life Depression Risk. https://digitalcommons.usu.edu/extension_curall/1774

[7] Coll, P.P. (2019) Healthy Aging: A Complete Guide to Clinical Management. Springer Nature, Berlin. https://doi.org/10.1007/978-3-030-06200-2

[8] Rakesh, G., Szabo, S.T., Alexopoulos, G.S. and Zannas, A.S. (2017) Strategies for Dementia Prevention: Latest Evidence and Implications. Therapeutic Advances in Chronic Disease, 8, 121-136. https://doi.org/10.1177/2040622317712442 
[9] Livingston, G., Sommerlad, A., Orgeta, V., Costafreda, S.G., Huntley, J., Ames, D., Mukadam, N., et al. (2017) Dementia Prevention, Intervention, and Care. The Lancet, 390, 2673-2734. https://doi.org/10.1016/S0140-6736(17)31363-6

[10] Dhana, K., Evans, D.A., Rajan, K.B., Bennett, D.A. and Morris, M.C. (2020) Healthy Lifestyle and the Risk of Alzheimer Dementia: Findings from 2 Longitudinal Studies. Neurology, 95, e374-e383. https://doi.org/10.1212/WNL.0000000000009816

[11] Wasserman, D., Iosue, M., Wuestefeld, A. and Carli, V. (2020) Adaptation of Evidence-Based Suicide Prevention Strategies during and after the COVID-19 Pandemic. World Psychiatry, 19, 294-306. https://doi.org/10.1002/wps.20801

[12] Reddeman, L., Bourgeois, N., Angl, E.N., Heinrich, M., Hillier, L., Finn, H., Ivers, N.M., et al. (2019) How Should Family Physicians Provide Physical Activity Advice? Qualitative Study to Inform the Design of an e-Health Intervention. Canadian Family Physician, 65, e411-e419. https://pubmed.ncbi.nlm.nih.gov/31515329/

[13] Keyworth, C., Epton, T., Goldthorpe, J., Calam, R. and Armitage, C.J. (2019) “It's Difficult, I Think It's Complicated": Health Care Professionals' Barriers and Enablers to Providing Opportunistic Behaviour Change Interventions during Routine Medical Consultations. British Journal of Health Psychology, 24, 571-592. https://doi.org/10.1111/bjhp.12368

[14] Greene, J., Hibbard, J.H., Alvarez, C. and Overton, V. (2016) Supporting Patient Behavior Change: Approaches Used by Primary Care Clinicians Whose Patients Have an Increase in Activation Levels. The Annals of Family Medicine, 14, 148-154. https://doi.org/10.1370/afm.1904

[15] Moore, A.E., Straus, S.E., Kasperavicius, D., Bell, N.R., Dickinson, J.A., Grad, R., Colquhoun, H., et al. (2017) Knowledge Translation Tools in Preventive Health Care. Canadian Family Physician, 63, 853-858. https://www.ncbi.nlm.nih.gov/pmc/articles/PMC5685446/pdf/0630853.pdf

[16] Canadian Institute for Health Research (2016) Knowledge Translation at CIHR. http://cihr-irsc.gc.ca/e/29418.html\#2

[17] Jeste, D.V. and Palmer, B.W. (2013) A Call for a New Positive Psychiatry of Ageing. British Journal of Psychiatry, 202, 81-83. https://doi.org/10.1192/bjp.bp.112.110643

[18] Thoo, V., Freer, J. and Cassidy, K.L. (2015) The Fountain of Health: Bringing Seniors' Mental Health Promotion into Clinical Practice. Canadian Geriatrics Journal, 18, 217. https://doi.org/10.5770/cgj.18.197

[19] Gough, A., Cassidy, B., Rabheru, K., Conn, D., Canales, D.D. and Cassidy, K.L. (2019) The Fountain of Health: Effective Health Promotion Knowledge Transfer in Individual Primary Care and Group Community-Based Formats. International Psychogeriatrics, 31, 173-180. https://doi.org/10.1017/S1041610218000480

[20] Drucker, P. (1954) The Practice of Management. Harper and Row, New York.

[21] Doran, G.T. (1981) There's a SMART Way to Write Management's Goals and Objectives. Journal of Management Review, 70, 35-36.

https://community.mis.temple.edu/mis0855002fall2015/files/2015/10/S.M.A.R.T-W ay-Management-Review.pdf

[22] Fountain of Health Toolkit (2021). https://fountainofhealth.ca/toolkit

[23] Fountain of Health Wellness App (2021). https://wellnessapp.ca/app/login

[24] Wen, C.P., Wai, J.P.M., Tsai, M.K., Yang, Y.., Cheng, T.Y.D., Lee, M.C., Wu, X., et al. (2011) Minimum Amount of Physical Activity for Reduced Mortality and Extended Life Expectancy: A Prospective Cohort Study. The Lancet, 378, 1244-1253. https://doi.org/10.1016/S0140-6736(11)60749-6 
[25] Holwerda, T.J., Deeg, D.J., Beekman, A.T., van Tilburg, T.G., Stek, M.L., Jonker, C. and Schoevers, R.A. (2014) Feelings of Loneliness, But Not Social Isolation, Predict Dementia Onset: Results from the Amsterdam Study of the Elderly (AMSTEL). Journal of Neurology, Neurosurgery \& Psychiatry, 85, 135-142. https://doi.org/10.1136/jnnp-2012-302755

[26] Steffener, J., Habeck, C., O’Shea, D., Razlighi, Q., Bherer, L. and Stern, Y. (2016) Differences between Chronological and Brain Age Are Related to Education and Self-Reported Physical Activity. Neurobiology of Aging, 40, 138-144.

https://doi.org/10.1016/j.neurobiolaging.2016.01.014

[27] Prince, M., Albanese, E., Guerchet, M. and Prina, A.M. (2014) World Alzheimer Report Dementia and Risk Reduction: An Analysis of Protective and Modifiable Factors. Alzheimer's Disease International (ADI), London. https://www.alz.co.uk/research/WorldAlzheimerReport2014.pdf

[28] Levy, B.R., Slade, M.D., Pietrzak, R.H. and Ferrucci, L. (2018) Positive Age Beliefs Protect against Dementia Even among Elders with High-Risk Gene. PLoS ONE, 13, e0191004. https://doi.org/10.1371/journal.pone.0191004

[29] Jeste, D.V., Blazer II, D.G., Buckwalter, K.C., Cassidy, K.L.K., Fishman, L., Gwyther, L.P., Feather, J., et al. (2016) Age-Friendly Communities Initiative: Public Health Approach to Promoting Successful Aging. The American Journal of Geriatric Psychiatry, 24, 1158-1170. https://doi.org/10.1016/j.jagp.2016.07.021

[30] Canadian Coalition for Seniors' Mental Health (2021). http://www.ccsmh.ca

[31] Fountain of Health (2021). http://www.fountainofhealth.ca

[32] Rockwood, K., Joyce, B. and Stolee, P. (1997) Use of Goal Attainment Scaling in Measuring Clinically Important Change in Cognitive Rehabilitation Patients. Journal of Clinical Epidemiology, 50, 581-588. https://doi.org/10.1016/S0895-4356(97)00014-0

[33] Krasny-Pacini, A., Hiebel, J., Pauly, F., Godon, S. and Chevignard, M. (2013) Goal Attainment Scaling in Rehabilitation: A Literature-Based Update. Annals of Physical and Rehabilitation Medicine, 56, 212-230. https://doi.org/10.1016/j.rehab.2013.02.002

[34] McGarrigle, L. and Rockwood, K. (2020) The Responsiveness of Goal Attainment Scaling Using Just One Goal in Controlled Clinical Trials: An Exploratory Analysis. Journal of Patient-Reported Outcomes, 4, 1-10. https://doi.org/10.1186/s41687-020-00196-8

[35] Cassidy, K.-L. and Cassidy, B. (2019) Positive Psychiatry: Neuroscience and Brain Health and Resilience. In: Fountoulakis, K. and Javed, A., Eds., Advances in Psychiatry, Springer Nature, New York, 329-345.

https://doi.org/10.1007/978-3-319-70554-5_20

[36] Sung, Y.T. and Wu, J.S. (2018) The Visual Analogue Scale for Rating, Ranking and Paired-Comparison (VAS-RRP): A New Technique for Psychological Measurement. Behavior Research Methods, 50, 1694-1715.

https://doi.org/10.3758/s13428-018-1041-8

[37] Voutilainen, A., Saaranen, T. and Sormunen, M. (2017) Conventional vs. e-Learning in Nursing Education: A Systematic Review and Meta-Analysis. Nurse Education Today, 50, 97-103. https://doi.org/10.1016/j.nedt.2016.12.020

[38] Cassidy, K., Vallis, M., Conn, D., Massie, A., Checkland, C., Parsons, D., Spence Mitchell, J. and Rabheru, K. (2020). Comparing a Clinician-Assisted and App-Supported Behavioral Activation Intervention to Promote Brain Health and Well-Being in Frontline Care. International Psychogeriatrics, 1-11. 


\section{https://doi.org/10.1017/S1041610220001325}

[39] Stoner, C. (2019) Positive Psychiatry/Psychology for Older Adults: A New and Important Movement But Robust Methodology Is Essential. International Psychogeriatrics, 31, 163-165. https://doi.org/10.1017/S1041610218002223

[40] Bauchner, H., Simpson, L. and Chessare, J. (2001) Changing Physician Behaviour. Archives of Disease in Childhood, 84, 459-462. https://doi.org/10.1136/adc.84.6.459

[41] Ellen, M.E., Panisset, U., de Carvalho, I.A., Goodwin, J. and Beard, J. (2017) A Knowledge Translation Framework on Ageing and Health. Health Policy, 121, 282-291. https://doi.org/10.1016/j.healthpol.2016.12.009

[42] Berkman, E.T. (2018) The Neuroscience of Goals and Behavior Change. Consulting Psychology Journal: Practice and Research, 70, 28.

https://doi.org/10.1037/cpb0000094 